\title{
A Study of Asphaltene-Resin Interactions
}

\section{Luiz C. C. Marques, ${ }^{* a}$ Juliana O. Pereira, ${ }^{b}$ André D. Bueno, ${ }^{a}$ Valdo S. Marques, ${ }^{a}$ Elizabete F. Lucas, ${ }^{c}$ Claudia R. E. Mansur, ${ }^{c}$ André L. C. Machado ${ }^{d}$ and Gaspar González ${ }^{d}$}

\author{
${ }^{a}$ Laboratório de Engenharia de Petróleo (LENEP), Universidade Estadual do Norte Fluminense (UENF), \\ Rod. Amaral Peixoto, km 163, Imboassica, 27925-310 Macaé-RJ, Brazil
}

${ }^{b}$ Escola de Química (EQ) da Universidade Federal do Rio de Janeiro (UFRJ), Av. Athos da Silveira Ramos, 149, Bloco E, 219141-909 Rio de Janeiro-RJ, Brazil

'Instituto de Macromoléculas (IMA) da Universidade Federal do Rio de Janeiro (UFRJ), Av. Horácio Macedo, 2030, 21949-598 Rio de Janeiro-RJ, Brazil

${ }^{d}$ Centro de Pesquisas Leopoldo Américo Miguez de Mello (CENPES), Petrobras, Av. Horácio Macedo, 950, Cidade Universitária, 21941-915 Rio de Janeiro-RJ, Brazil

Foi realizado um estudo para investigar a interação entre asfaltenos (em soluções de tolueno) e resinas (em soluções de $n$-heptano). Para entender melhor o tipo de interação entre essas frações, quantificou-se o consumo de resina quando asfaltenos (dissolvidos em tolueno) foram precipitados com uma solução de $n$-heptano contendo resina. Os resultados indicaram que a precipitação de asfaltenos ocorre juntamente com a redução na concentração de resina. Os perfis das isotermas de ligação indicaram que a saturação ocorreu em um caso, em quanto que o efeito cooperativo com posterior platô inicial foi observado para duas outras amostras. Estes resultados confirmaram a hipótese de que resinas podem adsorver em asfaltenos, mas não podem evitar floculação e precipitação de asfaltenos. Além disso, resultados de microcalorimetria sugeriram que a resina e asfalteno interagem por forças fracas de van der Waals. Estes resultados estão em contraste com a escola de pensamento predominante desde a década de 1940 que advoga que as resinas podem peptizar e estabilizar asfaltenos.

A study was carried out to investigate the interaction between asphaltenes (in toluene solutions) and resins (in $n$-heptane solutions). To better understand the type of interaction between these fractions, it was quantified the resin uptake when asphaltenes (dissolved in toluene) were precipitated by a resin-containing $n$-heptane solution. These results indicated the asphaltene precipitation occurs together with a reduction in the resin concentration. The binding isotherm profiles indicated that saturation occurred in one case, while collective association following an initial plateau was observed for the other two samples. These results confirmed the hypothesis that resins can adsorb on asphaltenes but cannot prevent asphaltenes from flocculating and precipitating. Furthermore, microcalorimetric results suggested that the resin and asphaltene interact by weak van der Waals forces. These results are in stark contrast with the school of thought prevalent since the 1940s that resins can peptize and stabilize asphaltenes.

Keywords: organic deposition, asphaltenes-resins interactions, binding isotherms

\section{Introduction}

Although many articles in the technical literature refer to asphaltenes and resins as related crude oil fractions, the interaction between these two solubility-class components is still a controversial subject. According to some authors,

*e-mail: luizccmarques@petrobras.com.br resins can act as dispersants that prevent the flocculation and deposition of the intrinsically unstable asphaltenes. ${ }^{1}$ Other authors, however, argue that both asphaltenes and resins are a family of compounds that combine to form a lyophilic colloid susceptible to phase separation under unfavorable compositional conditions, namely changes of pressure or temperature. ${ }^{2}$ More recently, even the existence of interactions between these two fractions 
has been questioned. ${ }^{3}$ According to Wang and Buckley, ${ }^{4}$ asphaltenes are not a specific family of chemicals with common functionally and varying molecular weight, like a homologous series. Their only unifying property is insolubility in a specified $n$-alkane.

Some of these contradictory views are based on the use of empirical or semi empirical models to interpret early results related to the colloidal stability of bitumen and/or bitumen fraction solutions ${ }^{5,6}$ and on the limited experimental information available in the literature specifically on this issue.

The fact is that asphaltenes flocculate and precipitate in different parts of the production system, thereby causing production impairment and/or formation damage. So, the asphaltene stabilization processes and/or interactions are an important flow assurance issue, thus warranting study by our research group. ${ }^{7-13}$

\section{Experimental}

Materials

The asphaltenes and resins were separated from three different samples: sample \# $i$, an asphaltenes-rich cut from a de-asphaltation processing unit (Duque de Caxias Refinery, Rio de Janeiro State, Brazil), sample \# ii, a biodegraded and extra-heavy crude oil from the Campos Basin, Rio de Janeiro State, Brazil, and sample \# iii, an asphaltene-rich deposit recovered from a subsea flowline during a pigging operation in Santos Basin, Santa Catarina State, Brazil. Toluene and $n$-heptane were analytical grade reagents purchased from Vetec Química Fina Ltda, Rio de Janeiro, Brazil, and were used without further purification.

\section{Asphaltenes extraction}

In the case of the samples obtained from the de-asphaltation unit (sample \# i) and the production deposit (sample \# iii), the following extraction process was used: approximately $15 \mathrm{~g}$ of solids were previously mixed with toluene and left to dissolve under mild agitation (magnetic stirring plate) overnight. Sample \# $\mathrm{i}$ was actually a hard lump which had to be heated (ca. $40-50{ }^{\circ} \mathrm{C}$ ) to be comminuted before being mixed with toluene. Likewise, sample \# iii was a brittle solid, but there was no difficulty to mix it with toluene. So, no heating was applied to help to dissolve this sample. In both cases, however, $5 \mathrm{~mL}$ of analytical-grade toluene were used to form a tacky asphaltene-in-toluene solution at room temperature. This solution was then kept under mild stirring at room temperature for $24 \mathrm{~h}$. Afterwards, the solution was transferred to a glass flask into which $1 \mathrm{~L}$ of analyticalgrade $n$-heptane was added. The whole flask was then wrapped with aluminum foil to prevent the photo-oxidation of the asphaltenes and kept under mild stirring for another $24 \mathrm{~h}$ at room temperature. After that, the whole solution in the flask was vacuum-filtered through $0.5 \mu \mathrm{m}$ membrane paper. The filtrate was separated for later $n$-heptanesoluble resin extraction. The dried solids separated by this filtration process (plus the filter membrane) were weighed. The membrane paper (containing the dried solids) was folded and properly placed on a Soxhlet extractor sample holder. Another $500 \mathrm{~mL}$ aliquot of $n$-heptane was added into the Soxhlet bottom flask. Both heating and vapor condensing systems of the apparatus were turned on to trigger the extraction process, which was carried out for at least $3 \mathrm{~h}$ or until a colorless liquid $n$-heptane phase was observed in the distillation flask. Following that, the solids (plus the filter membrane) were vacuum-dried at $60-70{ }^{\circ} \mathrm{C}$ for $12 \mathrm{~h}$ to a constant weight to quantify the concentration of asphaltenes (wt.\%) in the sample. Later, a second Soxhlet extraction process (this time using toluene as solvent) was performed on this solid material. The remaining solid material was also vacuum-dried at $60-70{ }^{\circ} \mathrm{C}$ to constant weight to quantify the inorganic solids. The toluene extract obtained was vacuum-dried in a rotating vacuum evaporator (Rotavapor IKA-Heizbad model HB 250) to separate and to quantify the (toluene soluble) asphaltenes.

On the other hand, the asphaltenes from sample \# ii were extracted and quantified using the IP-145 standard method. ${ }^{14}$

\section{Resin extraction}

The $n$-heptane filtrate recovered from the first asphaltene filtration step plus the asphaltene-free $n$-heptane extract recovered from the Soxhlet distillation flask were mixed up and vacuum-dried in the same rotating vacuum evaporator. The solid material obtained from this process was quantified as $n$-heptane-soluble resins. This extraction method implies that the resin fraction can contain other components, such as non-volatile polar fractions, aromatics and even some high molecular weight alkanes. However, the reason for using such method stems from the following facts: (i) the so-called resin fraction that elutes from the standard clay/gel fractionation column might be strongly affected by both the nature of the stationary phase and the polarity of the percolating carrier fluid. This is because some solid-catalyzed adsorption/ desorption phenomena can overstretch and break up the adsorved/absorbed molecules, thus generating smaller fragmented molecules that actually do not mimic the real 
resin molecules; and (ii) the resin extraction method here used is quite straightforward and simple, thus enjoying a significant advantage over solid-phase extraction by different polarity solvents.

\section{Characterization of asphaltenes and resins by elemental analysis}

The asphaltene and resin samples were characterized in terms of carbon, hydrogen, sulfur, nitrogen and oxygen contents. $\mathrm{C}, \mathrm{H}, \mathrm{S}$ and $\mathrm{N}$ were quantified in a ThemoFinningan Model EA 1 CHNS analyzer, and the oxygen content was determined in a Fisons EA 1108, oxygen analyzer apparatus.

\section{Resin concentration}

The resin concentration in $n$-heptane solutions was obtained by using a standard curve of resin concentration (mg L $\left.{ }^{-1}\right) v s$. absorbance. The solutions were prepared by dilution of aliquots taken from $10,000 \mathrm{mg} \mathrm{L}^{-1}$ resin stock solution. All the solutions were homogenized in a Thornton T-14 model ultrasonic bath to ensure complete dissolution of the crude fraction. The solution absorbance readings and related procedures were carried out at $22{ }^{\circ} \mathrm{C}$ in a Hach model 2010 spectrometer, operating at $550 \mathrm{~nm}$, and using a $1 \mathrm{~mm}$ optical path quartz cell. Straight lines with a good correlation factor $\left(\mathrm{r}^{2}\right)$ were obtained for the three resin samples in the concentration range of 500 to $1800 \mathrm{mg} \mathrm{L}^{-1}$. The experimental parameters of the absorbance $v s$. resin concentration curves are shown in Table 1.

Table 1. Experimental parameters of the absorbance vs. resin concentration curves

\begin{tabular}{lcc}
\hline Sample & Fitting curve & Correlation factor $\left(\mathrm{r}^{2}\right)$ \\
\hline \# i & $y=7.0 \times 10^{-5} x-0.009$ & 0.9942 \\
\# ii & $y=3.0 \times 10^{-5} x+0.001$ & 0.9902 \\
\# iii & $y=3.0 \times 10^{-5} x+0.007$ & 0.9397 \\
\hline
\end{tabular}

$y$ : absorbance; $x$ : resin concentration (ppm).

\section{Molecular weight of asphaltene and resin nanoaggregates}

The literature mentions that asphaltenes are prone to self-associate to form nanoaggregates even at very low concentrations in toluene solutions and also in live crude oil induced by centrifugation. ${ }^{15,16}$ These fundamentals must hold true for resins as well. Nonetheless, the limit concentration at which either asphaltenes or resins start forming aggregates, or clusters, was not investigated in our experimental studies.
In order to determine the molecular weight of asphaltenes and resin nanoaggregates, a rheological method originally described for polymer solutions and later adapted for bitumen and asphaltic fractions by Mack $^{17}$ and Eckert and Weetman ${ }^{18}$ was used. Here, it was assumed, however, that both the asphaltenes and resins were in high enough concentration (from 1 to $9 \mathrm{~g} \mathrm{~L}^{-1}$ ) in the test solutions to form nanoaggegates, or clusters. According to those authors, ${ }^{17,18}$ there is a linear relationship between the molecular weight of the solute and the logarithm of relative viscosity of the (diluted) solution (equation 1).

$\mathrm{M}_{\mathrm{w}}=\mathrm{k} \frac{\log \eta_{\mathrm{rel}}}{\mathrm{c}}$

where $\mathrm{M}_{\mathrm{w}}$ is the molecular weight, $\mathrm{k}$ is a constant of proportionality, $\eta_{\text {rel }}$ is the relative viscosity (solution viscosity to solvent viscosity ratio), and $\mathrm{c}$ is the solute concentration. First, a scoping trial was carried out to investigate the rheological behavior of the test solutions at shear rate range of 20 to $70 \mathrm{~s}^{-1}$. All the test solutions behave as Newtonian fluids (shear-independent viscosity) at shear rates ranging from 50 to $70 \mathrm{~s}^{-1}$. So, for the sake of simplicity, here it was selected the $60 \mathrm{~s}^{-1}$ shear rate to carry out the rheological study. All the viscosity readings were made at $25^{\circ} \mathrm{C}$, using a co-axial cylinder rheometer (Haake Mars Thermoscientific, model 25). Second, solutions of naphthalene and phenanthrene in toluene were prepared and rheological tests were carried out in an attempt to reproduce the value of $\mathrm{k}$ (constant of proportionality in equation 1 ) as per the experiments conducted by Eckert and Weetman. ${ }^{18}$ The value of $\mathrm{k}$ derived from our experiments $\left(3.97 \times 10^{-5}\right)$ differs by only $10.4 \%$, from the original one published by those authors $\left(3.6 \times 10^{-5}\right) .^{18}$

\section{Binding isotherms}

Figure 1 presents a sketch of the experimental procedure used for the binding studies. Different volumes of a $10 \mathrm{~g} \mathrm{~L}^{-1}$ resin stock solution in $n$-heptane were transferred to centrifuge tubes and the volume was completed to $25 \mathrm{~mL}$ with $n$-heptane. Then, $0.5 \mathrm{~mL}$ aliquots of an $8 \mathrm{~g} \mathrm{~L}^{-1}$ asphaltene stock solution in toluene (corresponding to a mass of $40 \mathrm{mg}$ of asphaltenes) were added. The solutions were hand shaken and left to stand under mild intermittent stirring for $120 \mathrm{~min}$. A preliminary test indicated that this period was enough to ensure the complete precipitation of the asphaltenes. Subsequently, the solutions were centrifuged (Novatech centrifuge) at $1500 \mathrm{rpm}$ for $30 \mathrm{~min}$ and aliquots of the supernatant were collected for absorbance measurements. 


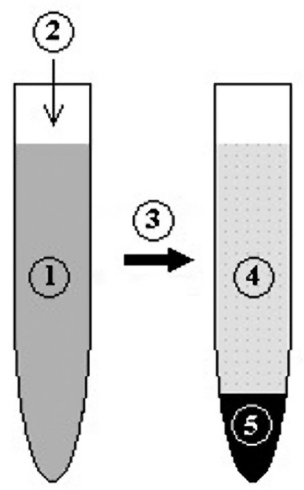

Figure 1. Experimental procedure used for uptake of resins by precipitating asphaltenes: (1) resins solution in $n$-heptane $\left(\mathrm{c}_{\mathrm{i}}\right)(2) 0.5 \mathrm{~mL}$ solution containing $40 \mathrm{mg}$ of asphaltenes in toluene, (3) centrifugation for $120 \mathrm{~min},(4)$ resins solution in $n$-heptane $\left(\mathrm{c}_{\mathrm{f}}\right)$ and (5) resins containing asphaltene flocks.

The resins uptake by the precipitating asphaltenes $\left(\mathrm{R}_{\mathrm{b}}\right)$ was calculated according to equation 2 .

$\mathrm{R}_{\mathrm{b}}=\frac{\left(\mathrm{c}_{\mathrm{i}}-\mathrm{c}_{\mathrm{f}}\right) \mathrm{v}}{\mathrm{m}}$

where $R_{b}$ is expressed in $\mathrm{mg}$ of resins per $\mathrm{g}$ of asphaltenes, $c_{i}$ and $c_{f}$ are the initial and final resin concentrations $\left(\mathrm{mg} \mathrm{L}^{-1}\right)$, respectively, $\mathrm{v}$ is the volume used in the precipitation tests $(\mathrm{L})$, and $\mathrm{m}$ is the mass of asphaltenes $(\mathrm{g})$.

\section{Asphaltene precipitation onset}

A NIR spectrophotometer (Bruker Optics model Matrix-F) operating at $1600 \mathrm{~nm}$ with a detection probe (10 $\mathrm{mm}$ optical path) was used in this part of the experimental study. The precipitation onset of sample \# iii asphaltenes, which are induced by $n$-heptane titration, was investigated in the presence of different concentrations of sample \# iii resins (from a mother solution of resins in $n$-heptane). This procedure was used to rank different crude oils according to their tendency to flocculate and precipitate their asphaltenes. ${ }^{19}$ In order to carry out the absorbance measurements, a $25 \mathrm{~g}$ sample of a toluene solution containing $0.8 \mathrm{~g}$ of sample \# iii asphaltenes was placed in a glass beaker and the tip of the detection probe was submerged in this solution in such a way that its optical path was completely submerged in the solution. The $n$-heptane titration was accomplished by a chromatographic pump (Varian Model Pro Star) operating at $2 \mathrm{~mL} \mathrm{~min}^{-1}$ titration rate up to a maximum sample dilution rate of $10 \mathrm{~mL} \mathrm{~g}^{1}$.

Prior plotting the absorbance vs. dilution $(\mathrm{mL}$ of heptane per $\mathrm{g}$ of sample) curves, the $n$-heptane absorbance (background value), derived from the resins in $n$-heptane solution added to the test solution, was subtracted from the original absorbance data.
These tests showed that the asphaltene precipitation onset value did not significantly change as the resin concentration was increased in the original asphaltenein-toluene solutions. So, it was decided to perform a new suite of spectrophotometric experiments to validate these data. This time, a spectrophotometer (Perkin-Elmer, model Lambda 45) operating at $750 \mathrm{~nm}$ was used to carry out the experiments. Asphaltene-in-toluene solutions, containing asphaltenes at $200 \mathrm{ppm}$ concentration, to produce an initial absorbance between 0.7 and 0.8 , were prepared. Afterward, different concentrations of resins (in $n$-heptane solutions) were incorporated in the original asphaltene solution. Then, the resultant solution was left overnight $(18 \mathrm{~h})$ at room temperature $\left(22^{\circ} \mathrm{C}\right)$. After hand-shaking, an aliquot was placed in a sealed quartz cuvette. Absorbance readings were taken as a function of time (between 1 and $90 \mathrm{~min}$ ). This procedure was applied to each of the pairs of asphaltenes and resins extracted from the three samples used in the study.

\section{Isothermal microcalorimetry}

A suite of experiments was performed to investigate asphaltene-resin interaction in an ultra-sensitive DSC (differential scanning calorimeter), microcalorimeter Setaram model micro DSC III. This apparatus has twin (upper and lower) isolated sample compartments, which can be interconnected by means of a plunger to determine the dilution- and interaction-enthalpies. The analytical procedure used in this study to measure the asphaltene-resin interactions is described in detail elsewhere. ${ }^{20}$ The microcalorimeter modus operandi was the following: solutions of $10 \mu \mathrm{L}$ of asphaltenes (5\%) in toluene and resins (5\%) in $n$-heptane were initially confined in the two syringe-shaped compartments inside the microcalorimeter measuring cell. By forcing a plunger downward, the solutions previously transferred to the apparatus compartments were allowed to commingle, thus allowing the interaction-enthalpy to be measured. The interaction-enthalpy of the pure solvent mixtures was measured in the same way.

Broadly speaking, the microcalorimetric study was specifically conceived to investigate the asphaltene-resin interaction. It comprises different and separate experiments where the enthalpy is systematically measured (for instance, the enthalpy of dilution of asphaltenes in toluene, the enthalpy of the mixture of toluene and $n$-heptane solvents, and the enthalpy of asphaltene precipitation in $n$-heptane). At the end, all these enthalpy values enable computing the final enthalpy of the resin-asphaltene interaction. 


\section{Results and Discussion}

\section{Characterization of asphaltenes and resins by elemental analysis}

Table 2 shows the chemical composition (\% mass) of the asphaltenes and resins extracted from the samples used in this study. As can be seen, the $\mathrm{C} / \mathrm{H}$ ratios for the three asphaltenes are very similar. The same applies to the $\mathrm{C} / \mathrm{H}$ ratio for the three resins. An explanation to this fact is that the extraction process for both resins and asphaltenes, which is based on solubility behavior, ends up extracting similar families of compounds no matter the origin of the sample. So, they should basically show the same $\mathrm{C} / \mathrm{H}$ ratio. In terms of chemical composition, sample \# i presents the highest sulfur content for both the resin and asphaltene fractions. This is because sample \# $\mathrm{i}$ is a high-boiling-point sulfur-rich cut from a de-asphaltation unit.

\section{Molecular weight of resin and asphaltene nanoaggregates}

In order to estimate the parameters that characterize the binding process, the molecular weight of both fractions (asphaltenes and resins) must be known. Studies reported by Mullins et al. ${ }^{21}$ point to asphaltene molecular weights in the range of 800 to $1000 \mathrm{Da}$. These figures nonetheless represent the ultimate or minimum molecular weight, corresponding to an individual layer according to Yen. ${ }^{22}$ These units can associate at concentrations as low as 50 to $100 \mathrm{mg} \mathrm{L}^{-1} \cdot{ }^{23}$ Under our experimental conditions, the formation of asphaltene and resin aggregates or clusters is expected, so it is hard to obtain their molecular weight because most of the optical methods like light scattering or fluorescence are not applicable and the molecular weight values obtained depend on concentration, temperature, solvent and the actual method used for the experimental measurements. At the other end of the spectrum, the experimental information on resins is rather scarce and neither the molecular weight nor the association of this fraction has been examined in detail.

It was applied a rheological method to determine the molecular weight for our range of asphaltene and resin concentrations, which was originally developed for polymer solutions and adapted for bitumen and petroleum asphaltic fractions by Mack, ${ }^{17}$ and later by Eckert and Weetman. ${ }^{18}$

All the asphaltenes and resins solutions presented Newtonian behavior at a wide range of shear rates. So, it was decided to take all the viscosity readings at 60 reciprocal seconds $\left(60 \mathrm{~s}^{-1}\right)$ at $25^{\circ} \mathrm{C}$.

A scoping trial was carried out to determine the value of $\mathrm{k}$ (equation 1) of diluted solutions of naphthalene and phenanthrene (to mimic the asphaltene molecules) in toluene. The value of $\mathrm{k}$ obtained $\left(3.975 \times 10^{-5}\right)$ shows good agreement with the original one published in the literature $\left(3.6 \times 10^{-5}\right)$. So, using this value for $\mathrm{k}$ and measuring the relative viscosity of a sequence of diluted solutions of asphaltenes in toluene, and resins in $n$-heptane, it was calculated the molecular weight of the asphaltenes (2105 Da) and resins (840 Da) separated from the deasphaltation residue (sample \# i). The molecular weights found here are consistent with those derived from mass spectrometric measurements. ${ }^{24}$ This information was used to determine the molar concentration of the asphaltenes and resins in solution.

\section{Binding isotherms}

The binding isotherms were constructed from the resin concentration determined by spectrophotometry. The absorbance readings for sample \# $\mathrm{i}$ were roughly a factor of two more than that obtained for the two other resins. This might either be due to the association of resins above the so-called critical nanoaggregation concentration (CNAC) or the fact the aromatic fractions are not similar in the three samples. As a matter of fact, the chemical composition of the resin from sample \# $\mathrm{i}$ is somewhat different from the

Table 2. Chemical composition (\% mass) of the asphaltenes and resins extracted from the samples used in this study

\begin{tabular}{|c|c|c|c|c|c|c|}
\hline \multirow{2}{*}{ Chemical composition } & \multicolumn{2}{|c|}{ Sample \# i } & \multicolumn{2}{|c|}{ Sample \# ii } & \multicolumn{2}{|c|}{ Sample \# iii } \\
\hline & $\mathrm{R} / \%$ & $\mathrm{~A} / \%$ & $\mathrm{R} / \%$ & $\mathrm{~A} / \%$ & $\mathrm{R} / \%$ & $\mathrm{~A} / \%$ \\
\hline Carbon & 84.0 & 93.4 & 86.5 & 85.0 & 88.1 & 83.3 \\
\hline Hydrogen & 10.8 & 7.4 & 12.7 & 6.9 & 11.5 & 8.2 \\
\hline Nitrogen & 0.5 & 1.0 & $<0.3$ & 0.8 & 0.8 & 2.1 \\
\hline Sulfur & 6.4 & 8.4 & 0.3 & 0.5 & 1.0 & 1.2 \\
\hline Oxygen & 0.9 & 2.1 & 0.8 & 1.7 & 1.0 & 2.6 \\
\hline $\mathrm{C} / \mathrm{H}$ ratio & 7.8 & 10.7 & 6.8 & 12.3 & 7.7 & 10.2 \\
\hline
\end{tabular}

R: resins; A: asphaltenes. 
other two resins. For instance, the sulfur concentration in sample \# $\mathrm{i}$ is almost ten times higher than that of the other two resins (from samples \# ii and \# iii).

Figure 2 shows the binding isotherm for the uptake of resins by asphaltenes. These curves correspond to the depletion of resin concentration in solutions containing resins dissolved in heptane resulting from the precipitation of the asphaltene fraction. Considering that the dispersions were equilibrated for long periods under moderate agitation to attain equilibrium between the precipitating solids and the dissolved species, here it was assumed that the curves represent equilibrium binding isotherms rather than simple entrapment of the resins by the precipitating asphaltenes. In the case of the deasphaltation residue (sample \# i), the isotherm profile (Figure 2a) represents a curve that may be analyzed in terms of multiple binding site equilibrium. On the other hand, the profile of the binding isotherms for sample \# ii (Figures 2b) and sample \# iii (Figure 2c) is characteristic of systems presenting the cooperativity effect at higher concentrations due to multilayer formation. An alternative explanation for these latter two binding isotherms is the formation of resin aggregates at higher concentrations followed by the binding of these aggregates by the asphaltenes. If this is the case, it would imply that resins aggregate at concentrations around $250-200 \mathrm{mg} \mathrm{L}^{-1}$. Both assumptions, however, require further studies, which can help shed light on the rheological behavior of asphaltenerich heavy crude oils.

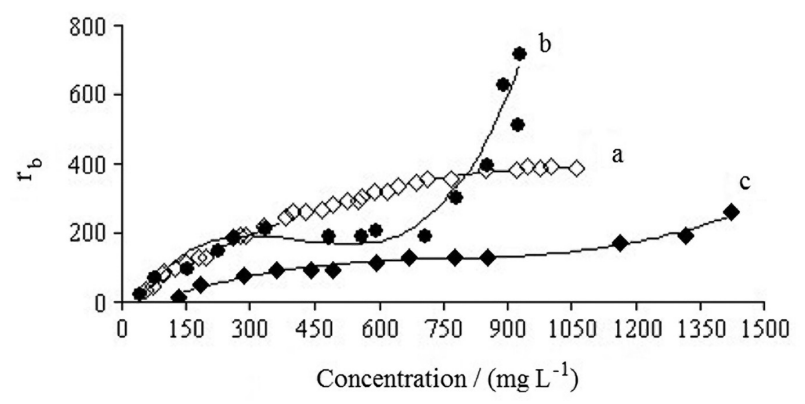

Figure 2. Binding isotherm for the uptake of resins by asphaltenes (rb, mg of resins per $g$ of asphaltenes), from: (a) sample \# $i$, an asphaltene-rich cut from a de-asphaltation processing unit, (b) sample \# ii, a biodegraded and extra-heavy crude oil from a Brazilian oilfield, and (c) sample \# iii, an asphaltene-rich deposit recovered from a subsea flowline during a pigging operation in a Brazilian oilfield.

A similar cooperativity effect is observed beyond the critical micelle concentration (CMC) for sodium dodecyl sulfate (SDS) on hydrophobized hydroethyl cellulose, ${ }^{25}$ and also for Triton-X surfactant on silica. ${ }^{26}$

Conversely, the binding of resins (R) by each independent site of the asphaltenes (A) can be represented by the following equilibrium and its corresponding dissociation constant $\left(\mathrm{K}_{\mathrm{d}}\right){ }^{27}$

$\mathrm{AR} \rightarrow \mathrm{A}+\mathrm{R}$

$\mathrm{k}_{\mathrm{d}}=\frac{(\mathrm{A})(\mathrm{R})}{\mathrm{AR}}$

The overall binding process can be described by the following alternative equations: ${ }^{27}$

$$
\begin{aligned}
& \frac{1}{\mathrm{r}_{\mathrm{b}}}=\frac{1}{\mathrm{n}}+\frac{\mathrm{k}_{\mathrm{d}}}{\mathrm{nc}_{\mathrm{r}}} \\
& \frac{\mathrm{r}_{\mathrm{b}}}{\mathrm{c}_{\mathrm{r}}}=\frac{\mathrm{n}}{\mathrm{K}_{\mathrm{d}}}-\frac{\mathrm{r}_{\mathrm{b}}}{\mathrm{K}_{\mathrm{d}}}
\end{aligned}
$$

where $r_{b}$ is the ratio between the concentration of resins bound to the asphaltenes and the total asphaltene concentration, $\mathrm{c}_{\mathrm{r}}$ is the equilibrium resin concentration and $\mathrm{n}$ is the number of independent binding sites per mole of asphaltenes.

The plots $\left(\mathrm{r}_{\mathrm{b}}^{-1} \times \mathrm{c}_{\mathrm{r}}^{-1}\right)$ obtained by equation 5 are named Hughes-Klotz plots and the ones $\left(\mathrm{r}_{\mathrm{b}} \mathrm{c}_{\mathrm{r}}^{-1} \times \mathrm{r}_{\mathrm{b}}\right)$ obtained from equation 6 are named Scatchard plots. The HughesKlotz double reciprocal plots for the binding of resins by precipitating asphaltenes are presented in Figures 3a (sample \# i), 3b (sample \# ii) and 3c (sample \# iii). The last two plots, however, were built by using only the data points before the end of the plateau (Figures $2 b$ and $2 c$ ) to avoid the risk of leading to misinterpretations due to possible cooperative effects.

The observed slight deviation from linear tendency may be due to two different effects: cooperative effects (resin-resin interaction) followed by adsorption on the asphaltene binding sites or simply the beginning of the classic two-step formation of a double layer of resin on the asphaltene binding sites.

The values of $n$ (the number of independent binding sites per mol of asphaltenes) and the dissociation constant $\left(\mathrm{k}_{\mathrm{d}}\right)$ (equation 4 ) obtained for the binding process are presented in Table 3.

Table 3. Parameters ( $n$ and $k_{d}$ ) obtained for the binding process

\begin{tabular}{lcc}
\hline Sample & $\mathrm{n}$ & $\mathrm{k}_{\mathrm{d}} /\left(\mathrm{mol} \mathrm{dm}^{-3}\right)$ \\
\hline \# i & 1.8 & $9.5 \times 10^{-4}$ \\
\# ii & 1.1 & $5.2 \times 10^{-2}$ \\
\# iii & 2.3 & $7.7 \times 10^{-4}$ \\
\hline
\end{tabular}

The resin-to-asphaltene ratio shows good agreement with previously reported results for Marlim crude oil (Rio de Janeiro State, Brazil). ${ }^{18}$ However, it turns out that the 

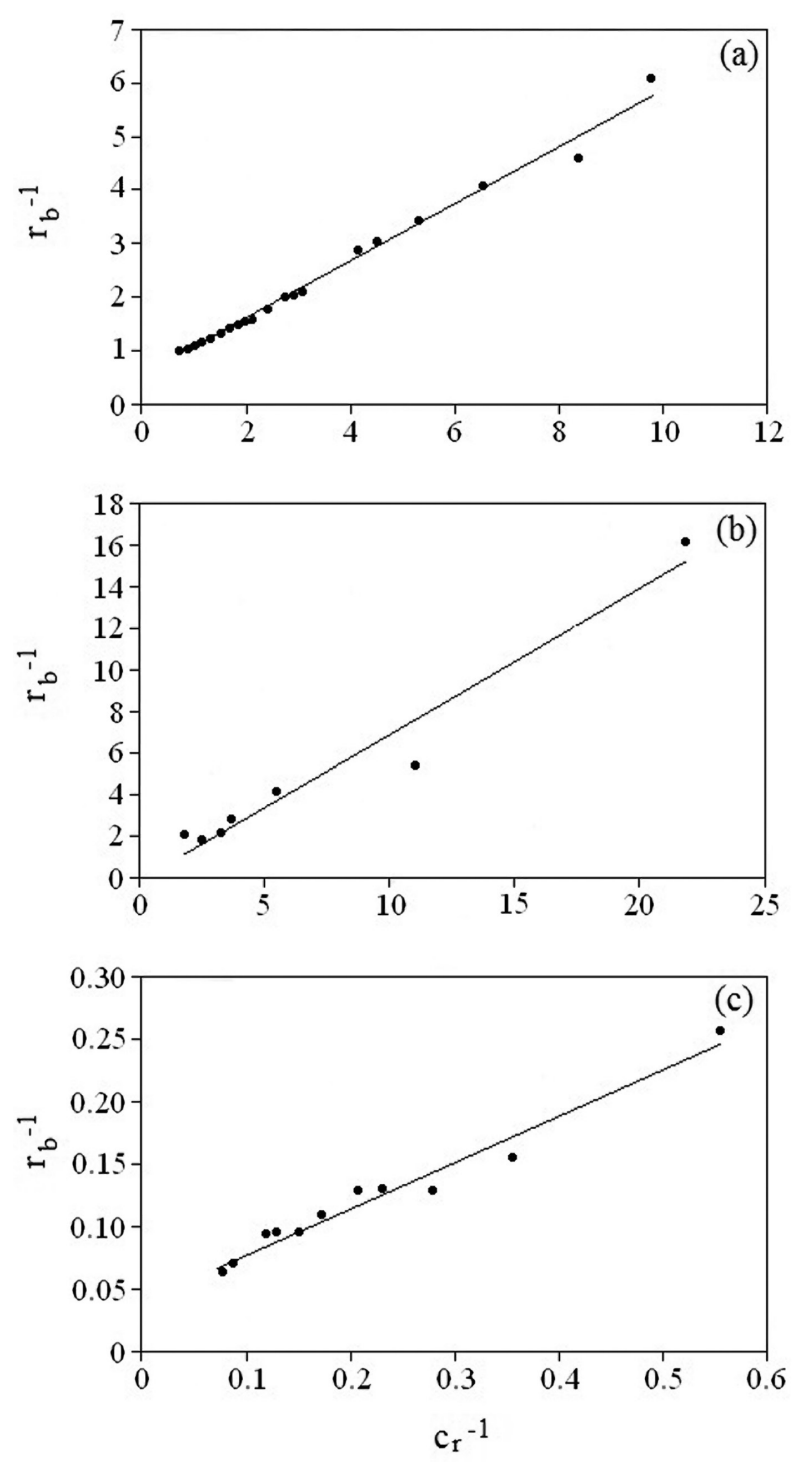

Figure 3. Hughes-Klotz double reciprocal plot for: (a) sample \# i, (b) sample \# ii (using the first 7 data points only) and (c) sample \# iii (using the first 11 data points only).

dissociation constant values are spaced out by two orders of magnitude. This could be due to the fact that the samples used in this study are from different sources and went through different separation processes, thus being stripped from part of their original resins and/or other components.

\section{Asphaltenes precipitation onset}

The absorbance $v s$. time plots are presented in Figures 4 , 5 and 6, where blank is the asphaltenes (200 ppm) in toluene. In broad terms, the asphaltene precipitation onset tests performed enabled us to conclude that the addition of resins (within the used range of concentration) neither prevent the asphaltenes from flocculating nor from precipitating. However, this may not hold true for higher resin concentrations. So, further studies on this specific issue are strongly recommended.

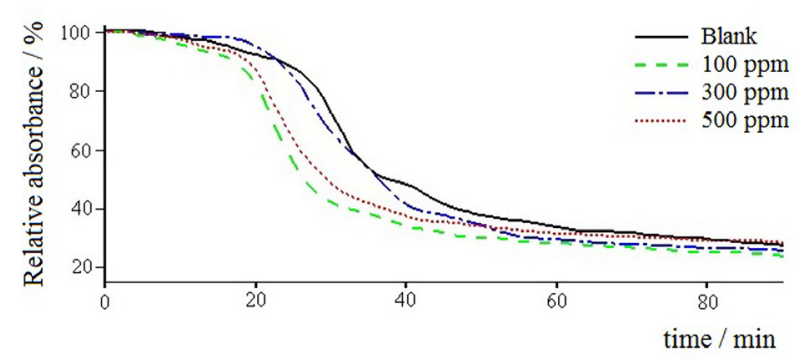

Figure 4. Absorbance of sample \# i asphaltenes (200 ppm concentration) as a function of the concentration of resins dissolved in $n-\mathrm{C}_{7}(\mathrm{ppm})$ and time.

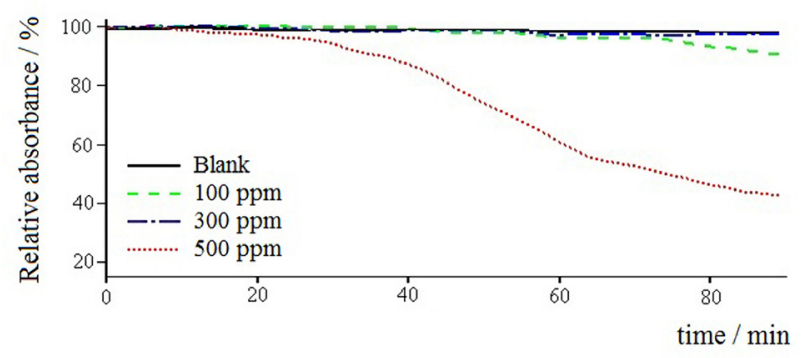

Figure 5. Absorbance of sample (\# ii) asphaltenes (200 ppm concentration) as a function of the concentration of resins dissolved in $n-\mathrm{C}_{7}(\mathrm{ppm})$ and time.

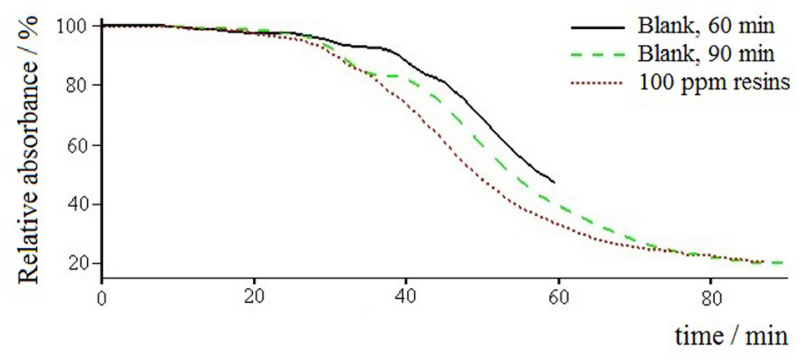

Figure 6. Absorbance of sample \# iii asphaltenes ( $200 \mathrm{ppm}$ concentration) as a function of the concentration of resins dissolved in $n-\mathrm{C}_{7}(\mathrm{ppm})$ and time.

In addition, another battery of asphaltene-resin interaction experiments was performed. This time, the resins were replaced by a commercial (polyolefin-based) asphaltene dispersant ( $25 \mathrm{ppm}$ concentration). The aim of this set of tests was twofold: (i) to investigate the performance of the commercial asphaltene dispersant, and (ii) to compare it with the previous one provided by resins at different concentrations. In the experiments, the absorbance curves for the asphaltene-dispersant solutions remained practically constant over the experimental time. Figure 7 shows the results obtained for sample \# $i$ and similar results were obtained for both asphaltenes samples \# ii and \# iii. This is doubtless an indication that the asphaltenes do not flocculate or precipitate in the presence of the commercial dispersant. Broadly speaking, these experiments show 
that this additive has excellent performance as asphaltene dispersant, even at low concentrations.

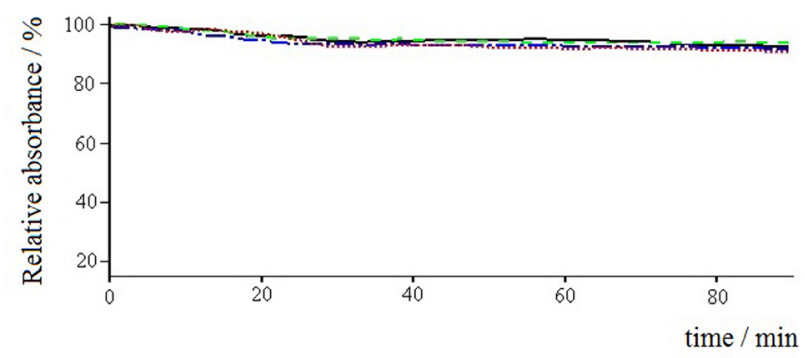

Figure 7. Quadruplicated absorbance readings of sample \# i asphaltenes ( $200 \mathrm{ppm}$ concentration) as a function of time. Resins were replaced by a commercial asphaltene dispersant at $25 \mathrm{ppm}$ concentration.

Isothermal microcalorimetry

Heat exchange is a ubiquitous phenomenon associated with chemical reactions such as molecular binding, association (polymerization reactions) and chemisorption, and physical phenomena such as phase transitions, molecular aggregation, molecular adsorption, etc. So, the use of calorimetric or microcalorimetric methods to determine enthalpy, entropy or free energy can be insightful to infer the nature and magnitude of forces associated with the phenomenon(a) under investigation. ${ }^{28-32}$

Different volumes of asphaltene-in-toluene solutions, resin-in- $n$-heptane solutions and also pure solvents were mixed in this experimental work. Although, it is indisputable that the changes in the solubility parameter affect the interaction between solutes from different solvents, our aim here was to force the asphaltenes (from the toluene solution) to come out of solution, by adding a bad solvent (resins containing $n$-heptane), thus generating large specific surface area of asphaltene particles (colloidal ones) with which resins (in $n$-heptane solution) could promptly interact.

The experimental asphaltene-resin interactionenthalpy values determined by ITC are quite small, hovering around $3-5 \mathrm{~kJ} \mathrm{~mol}^{-1}$. This denotes that (weak) van der Waals forces are responsible for the asphaltene/resin interaction, or in other words, there is no strong interaction between these two heavy petroleum fractions. It must be said, however, that the measured enthalpy values are slightly above the microcalorimeter background noise. Due to this, in quite a number of tests, the average enthalpy values showed a fairly large standard deviation. However, these results are in good agreement with those in the literature. ${ }^{33}$ Further microcalorimetric studies using more concentrated asphaltene and resin solutions are strongly recommended.

\section{Conclusions}

Under the experimental conditions used here, resins (up to $1 \%$ concentration) are able to adsorb on asphaltene particles but they cannot prevent them from flocculating. These results are in stark contrast with a school of thought prevalent since the 1940s that resins can both peptize and stabilize asphaltenes. On the other hand, these results are in accordance with the recent work of Yarrantov and Masliyah, ${ }^{34}$ who described both asphaltenes and resins as families of compounds that share similar characteristics, and are keen to self-associate, so they should not be considered different fractions.

A commercial polyolefin-based asphaltene inhibitor, even at low dosage (25 ppm), was able to prevent the flocculation and precipitation of the three asphaltenes used in the experimental study.

The molecular weight of the asphaltenes (2105 Da) and resins (840 Da) obtained here by rheology are consistent with the ones obtained by Hortal et al. ${ }^{23}$ using mass spectrometry.

The profiles of the binding isotherms for samples \# ii and \# iii are characteristic of systems that exhibit cooperative effects. At higher concentrations (250-300 $\mathrm{mg} \mathrm{L}^{-1}$ ), either multilayers of resins are formed or there is an initial resin aggregation process followed by the binding of these aggregates by the asphaltenes. This assumption deserves further study, which can contribute to the understanding of the rheological behavior of heavy crude oils.

The Hughes-Klotz double reciprocal plots enabled us to calculate the number of independent sites per mol of asphaltenes, which are: 1 for sample \# ii and roughly 2 for the two other samples. These values are similar to the one obtained for crude oil from the Marlim Field (Campos Basin, Rio de Janeiro State, Brazil).${ }^{19}$ Conversely, the dissociation constant $\left(\mathrm{k}_{\mathrm{d}}\right)$ values are spaced out by two orders of magnitude. This can be due to the uniqueness of the samples (from different sources) used in the study. No further studies, however, were carried out to support this argument.

The interaction enthalpy between asphaltenes and resins was determined by isothermal microcalorimetry and hovers around 3-5 $\mathrm{kJ} \mathrm{mol}^{-1}$. This value is typical of (relatively weak) van der Waals forces and is useful to define the ionic character of both asphaltene and resin molecules: large structures and/or long chain molecules with low polarity.

\section{Acknowledgements}

The authors thank Petrobras and Universidade Estadual do Norte Fluminense (UENF/LENEP) for the permission 
to publish the paper, and the Conselho Nacional de Desenvolvimento Científico e Tecnológico (CNPq) for researcher grants.

\section{References}

1. Leontaritis, K. J.; Mansoori, G. A.; SPE International Symposium on Oilfield Chemistry, San Antonio Texas, 4-6, Feb, SPE 16258,1987.

2. Hirschberg, A.; de Jong, L. J.; Shipper, B. A.; Mejer, J. G.; Soc. Pet. Eng. J. 1984, 24, 283.

3. Mullins, O. C.; Betancourt, S. S.; Cribbs, M. E.; Dubost, F. X.; Creek, J. L.; Andrews, A. B.; Venkataraman, L.; Energy Fuels 2007, 21, 2785.

4. Wang, J. X.; Buckley, J. S.; Energy Fuels 2003, 17, 1445.

5. Nellesteyn, F. J.; J. Pet. Technol. 1924, 10, 311.

6. Pfeiffer, J.; Saal, R. N.; J. Phys. Chem. 1940, 6, 114.

7. Lucas, E. F.; Mansur, C. R. E.; Spinelli, L.; Queirós, Y. G. C.; Pure Appl. Chem. 2009, 81, 473.

8. Moreira, L. F. B.; González, G.; Lucas, E. F.; Polímeros 1998, 8,46 .

9. Sousa, M. A.; Oliveira, G. E.; Lucas, E. F.; González, G.; Prog. Colloid Polym. Sci. 2004, 128, 283.

10. González, G.; Souza, M. A.; Lucas, E. F.; Energy Fuels 2006, 20, 2544.

11. Oliveira, G. E.; Mansur, C. R. E.; González, G.; Souza, W. F.; Lucas, E. F.; J. Dispersion Sci. Technol. 2007, 28, 1.

12. Carbonezi, C. A.; Almeida, L. C.; Araújo, B.; Lucas, E. F.; González, G.; Energy Fuels 2009, 23, 1249.

13. Maia Filho, D. C.; Ramalho, J. B. V. S.; Spinelli, L.; Lucas, E. F.; Colloids Surf., A 2012, 396, 208.

14. IP-143 - DIN 51595 Standard Method for Determination of Asphaltenes (Heptane-Insoluble) in Crude Petroleum.

15. Indo, K.; Ratulowski, J.; Jindoruk, B.; Gao, J.; Zuo, J.; Mullins, O. C.; Energy Fuels 2009, 23, 4460.

16. Goual, L.; Sedghi, M.; Zeng, H.; Mostowfi, F.; McFarlane, R.; Mullins, O. C.; Fuel 2011, 90, 2480.
17. Mack C.; J Phys. Chem. 1932, 36, 2901.

18. Eckert, G. W.; Weetman, B.; J. Ind. Eng. Chem. 1947, 39, 1512.

19. González, G.; Neves, G. B. M.; Saraiva, S. M.; Sousa, M. A.; Lucas, E. F.; Energy Fuels 2003, 17, 879.

20. Mansur, C. R. E.; Aguiar, J. I. S.; Silva, P. R. S.; Lucas, E. F.; Gonzalez, G.; French-Brazilian Meeting on Polymers - FBPOL 2008, vol. 4, Florianopolis, SC, Brazil, 2008, p. 20-25.

21. Mullins, O.; Sheu, E. Y.; Hammami, A.; Marshall, A. G.; Asphaltenes, Heavy Oils and Petroleomics; Springer: New York, 2002.

22. Yen, T. F.; Asphaltic Materials, in: Encyclopedia of Polymer and Enigeering, $2^{\text {nd }}$ ed., Wiley \& Sons: New York, 1990, p. 110.

23. Hortal, A. R.; Martinez-Haya B.; Lobato, M. D.; Pedrosa, J. M.; Lago, S.; J. Mass Spectrom. 2006, 41, 960.

24. Mullins, O. C.; Betancourt, S. S.; Cribbs, M. E.; Dubost, F.X.; Creek, J. L.; Andrews, A. B.; Venkataramanan, L.: Energy Fuels 2007, 21, 2785.

25. Guillemet, F.; Picullet, L. J.; Phys. Chem. 1955, 99, 9201.

26. Gonzalez, G.; Louvisse, A. M. T.; Langmuir 1998, 5, 26.

27. Price, N.C.; Dwek, R. A.: Principles and Problems in Physical Chemistry for Biochemists, $2^{\text {nd }}$ ed.; Oxford Univ Press: Oxford, 1979.

28. Olofsson, G.; Loh, W.; J. Braz. Chem. Soc. 2009, $20,577$.

29. Vieira, L. C.; Buchuid, M. B.; Lucas, E. F.; Energy Fuels 2010 , 24, 2208.

30. Vieira, L. C.; Buchuid, M. B.; Lucas, E. F.; Energy Fuels 2010 , 24, 2213.

31. Vieira, L. C.; Buchuid, M. B.; Lucas, E. F.; J. Appl. Polym. Sci. 2012, in press. DOI 10.1007/s10973-012-2252-3.

32. Vieira, L. C.; Buchuid, M. B.; Lucas, E. F.; J. Therm. Anal. Calorim. 2012, in press. DOI 10.1007/s10973-012-2252-3.

33. Lisitza, N.; Freed, D. E.; Sen, P. N.; Song, Y. Q.; Energy Fuels 2009, 23, 1189.

34. Yarranton, H. W.; Masliyah, J. H.; AIChE J. 1996, 42, 3333.

Submitted: January 27, 2012

Published online: October 19, 2012 